\title{
Difference of neuromuscular responses by additional loads during plyometric jump
}

\author{
Sungwoo Kang* \\ XION Sports Performance Training Center, Seoul, Korea
}

Plyometric training is a training method to increase the motor output, stretch-shortening cycle which could be associated with power output. To increase the neuromuscular output, various training variables have been incorporated in training programs. Weight vest is one of the variables to develop it. However, how much load can effectively develop the neural response is still not clearly understood. The aim of this study was to identify the effects of additional external loads on neuromuscular response of lower body during plyometric jump. Total 19 men performed jump tests with weight vest (two jumps in each additional load; $0 \%, 10 \%, 15 \%$ and $20 \%$ of bodyweight [BW]). During the tests, neuromuscular responses of lower extremity were measured. In vertical jump, $0 \% \mathrm{BW}$ group was higher than the other heavier loads. In rate of force development (RFD), 10\%BW was higher than $15 \% \mathrm{BW}$ and $20 \% \mathrm{BW}$. In $0-30$ msec of interval RFD, the heavier load groups were greater than $0 \% \mathrm{BW}$ and in $0-50 \mathrm{msec}, 15 \% \mathrm{BW}$ and $20 \% \mathrm{BW}$ were higher than $0 \% \mathrm{BW}$. In neuromuscular efficiency (NME), $15 \% \mathrm{BW}$ and $20 \% \mathrm{BW}$ were greater than $0 \% \mathrm{BW}$ in ankle joint. This research indicated that plyometric jump with additional load causes greater RFD and NME of lower extremity compared with jump training without additional load. During weight vest plyometric jump, $10 \%-20 \%$ of BW load is advantageous to NME of lower body and $10 \%$ of BW load is effective to develop RFD of lower extremity.

Keywords: Plyometric training, Weight vest, Power, Neuromuscular efficiency, Rate of force development

\section{INTRODUCTION}

Plyometric training is one of popular training methods to enhance sports performance (Markovic, 2007) and has been known to increase the motor output, stretch-shortening cycle (SSC) which could be associated with power output and force production (Komi and Bosco, 1978).

Previous researches reported that plyometric training enhances many sports performance variables such as muscle strength, power, vertical jump height, agility, sprint performance, and neuromuscular response (Faigenbaum et al., 2007; Fouré et al., 2012; Guilhem et al., 2010; Häkkinen, 1994; Rahman and Naser, 2015) and plyometric jump training is effective to increase performance and prevent injuries from games or repetitive practices (Aboodarda et al., 2014; Wilkerson et al., 2004).

The SSC is important neuromuscular function to produce power (Leukel et al., 2008). It consists of eccentric (stretch), amortiza-

tion, and concentric (shortening) phase. In eccentric phase that musculotendinal portion is lengthened, potential elastic energy in muscles and tendons is stored from the lengthening (Nichols and Houk, 1976) and in concentric contraction phase, explosive force or power takes place through release of the elastic energy transferred from the lengthening (Komi and Bosco, 1978). Amortization is the time between the end of lengthening phase and the initial of concentric phase and when the time is delayed, the amount of elastic energy stored in the muscles and tendons is decreased. As a result, the neuromuscular ability to produce force and power can be diminished (Bosco and Komi, 1979; Moore and Schilling, 2005).

To increase the neuromuscular output during plyometric training, various training variables (jump height, landing surface, loads, training tools, etc.) have been incorporated to training programs. Applying additional load was suggested as the best training stimulation to develop power output (Hoffman et al., 2005).
${ }^{*}$ Corresponding author: Sungwoo Kang (D) https://orcid.org/0000-0003-3458-8343 XION Sports Performance Training Center, 2F Spoworld, 563 Eonju-ro, Gangnam-gu, Seoul 06135, Korea

Tel: +82-2-567-8857, Fax: +82-2-538-8852, E-mail: atdavidkang@gmail.com Received: August 26, 2018 / Accepted: November 9, 2018
This is an Open Access article distributed under the terms of the Creative Commons Attribution Non-Commercial License (http://creativecommons.org/licenses/by-nc/4.0/) which permits unrestricted non-commercial use, distribution, and reproduction in any medium, provided the original work is properly cited. 
On the other hand, optimal level of load application is critical to maximize neuromuscular responses which enhance power output (Barnes et al., 2015; Fatouros et al., 2000; Kraska et al., 2009).

However, it has been reported that during plyometric jump, additional load can increase ground contact time and the delayed contact time is associated with the neuromuscular responses (Santos-Concejero et al., 2013). The longer ground contact time caused by heavy load results in decrease of neuromuscular efficiency (NME) to produce power (Sáez-Sáez de Villarreal et al., 2010).

Although using additional loads in plyometric training is prevalent, how much load can effectively develop neuromuscular output through plyometric training is still not clearly understood (Leontijevic et al., 2012). Thus, this study aimed to identify the effects of additional external loads on neuromuscular response of lower body during jumping and how much additional load works for enhancing neuromuscular output during plyometric jump training.

\section{METERIALS AND METHODS}

\section{Participants}

Total 20 collegiate male subjects participated in this research. Measurement data of 19 subjects, except for 1 subject who had a problem on jump, was used for analyzing the results of this study (Table 1). The subject who had problem on cardiovascular and neuromuscular functions for last 6 months before this study and on jump and landing motions was excluded from this research. All subjects were informed of the potential risks associated with this experiment before the test. This study was reviewed and approved by the committee on research ethics of the Kookmin University before all the procedures began (KMU-201507-HR-064-R1).

\section{Measurements procedure}

All subjects performed countermovement jump (CMJ) with weight vest. 4 different external loads (0\%, 10\%, 15\%, and $20 \%$ of bodyweight $[\mathrm{BW}]$ ) were used for this study. $2 \mathrm{CMJ}$ tests at

Table 1. The characteristics of the subjects

\begin{tabular}{lc}
\hline Characteristic & Mean \pm SD \\
\hline Age $(\mathrm{yr})$ & $24.37 \pm 1.57$ \\
Height $(\mathrm{cm})$ & $177.24 \pm 7.32$ \\
Weight $(\mathrm{kg})$ & $77.23 \pm 11.29$ \\
$\%$ Bodyfat $(\%)$ & $16.04 \pm 5.33$ \\
Body mass index $\left(\mathrm{kg} / \mathrm{m}^{2}\right)$ & $24.48 \pm 2.79$
\end{tabular}

$\mathrm{SD}$, standard deviation. each additional load were carried out. 5-min rest was provided between tests of different additional loads to prevent fatigue from jumps. During the jump tests, peak power was measured using GymAware (Kinetic Performance Technology, Canberra, Australia). Vertical jump height, muscle onset time, rate of force development (RFD) and NME of knee and ankle joints were measured using electromyography (EMG) and motion analysis system.

\section{Electromyography}

Muscle activation during CMJ was measured by using a wireless EMG device (BTS FREEEMG 1000, BTS Bioengineering, Milano, Italy). Prior to attachment of electrodes, the skin was shaved and cleaned using alcohol. The electrodes were attached to rectus femoris (knee) and soleus (ankle) of the dominant lower extremity. The EMG data was full-wave rectified and low-pass filtered at $50 \mathrm{~Hz}$. Raw EMG signals were collected with a bandpass filter of $20-500 \mathrm{~Hz}$, sampled at $1,000 \mathrm{~Hz}$ and rectified. 3 standard deviation above the mean activity on $100 \mathrm{msec}$ of resting period was used to determine onset time of EMG activity.

\section{Motion analysis}

Joint moments of knee and ankle and maximal vertical jump height were measured using motion capture analysis. The three-dimensional kinematics of the lower extremity were evaluated during CMJ using eight infrared cameras $(250 \mathrm{~Hz}$ Oqus 5 , Qualisys, Göteborg, Sweden). Qualisys track manager (QTM, Qualisys) was used for collecting data. Markers were attached to greater trochanter (GT), anterior superior iliac spine, iliac crest, posterior superior iliac spine, sacrum, medial/lateral epicondyle of the femur, medial/lateral malleolus, calcaneous and 1st, 2nd, and 5th head metaphalanges of the foot.

\section{Data processing}

RFD was evaluated by two types of RFD: (a) RFD to peak EMG amplitude $\left(\mathrm{RFD}_{\text {peak }}\right)$ and (b) interval RFDs in time intervals of $0-30,0-50$, and $0-200$ msec relative to start of jump ( $R_{F D}$ interval $)$ (Aagaard et al., 2002).

NME was defined as the ratio of joint moment to muscle activation (Aragão et al., 2015). NME was calculated by the equation; $\mathrm{NME}=\sum$ work (torque) $/$ Lmuscle activation. NME of knee and ankle joints were evaluated.

Vertical jump height was determined by difference of heights of GT at start position and at maximal jump. To calculate vertical jump height, height of GT at standing position to start jump and maximal height of GT during jump were measured. 
Table 2. Vertical jump, peak power, and muscle onset time by additional loads

\begin{tabular}{|c|c|c|c|c|c|}
\hline Variable & $0 \%$ & $10 \%$ & $15 \%$ & $20 \%$ & Posthoc \\
\hline \multirow[t]{4}{*}{ Vertical jump height (cm) } & $45.33 \pm 4.92$ & $41.95 \pm 4.35^{a, b l}$ & $40.69 \pm 4.05^{c l}$ & $39.09 \pm 3.95^{\mathrm{d} l}$ & $10 \%(P=0.019)$ \\
\hline & & & & & $0 \%>15 \%(P=0.002)$ \\
\hline & & & & & $20 \%(P=0.000)$ \\
\hline & & & & & $10 \%>15 \%(P=0.046)$ \\
\hline Peak power (W) & $7,090.05 \pm 2,074.10$ & $6,218.61 \pm 1,825.28$ & $5,924.18 \pm 1,667.41$ & $5,710.50 \pm 1,604.81$ & $\mathrm{NS}(P=0.101)$ \\
\hline \multicolumn{6}{|l|}{ Muscle onset time (msec) } \\
\hline Knee (RF) & $254.56 \pm 48.99$ & $242.29 \pm 78.32$ & $257.55 \pm 72.82$ & $253.58 \pm 80.26$ & $\mathrm{NS}(P=0.918)$ \\
\hline Ankle (Sol) & $278.68 \pm 75.08$ & $292.50 \pm 281.58$ & $281.58 \pm 97.69$ & $295.66 \pm 78.24$ & $\mathrm{NS}(P=0.908)$ \\
\hline
\end{tabular}

Values are presented as mean \pm standard deviation.

$\mathrm{NS}$, not significance; RF, rectus femoris; Sol, soleus.

${ }^{a} 0 \%$ vs. $10 \%, P<0.05 .{ }^{b} 10 \%$ vs. $15 \%, P<0.05 .{ }^{c} 0 \%$ vs. $15 \%, P<0.01 .{ }^{\text {dd }} 0 \%$ vs. $20 \%, P<0.001$

Peak power was measured by using GymAware power system (GymAware, Kinetics, Australia). Strap of the device was connected to the waists of the subjects. Maximal value of powers measured during $2 \mathrm{CMJ}$ tests was recorded as peak power value.

\section{Statistical analysis}

All data from this study was analyzed by IBM SPSS ver. 18.0 (IBM Co., Armonk, NY, USA). All values were expressed as mean and standard deviation. One-way analysis of variance (ANOVA) was performed to analyze the difference of neuromuscular responses by additional loads during CMJ. When there are significant differences between groups, least significant difference was carried out for post hoc analysis. Significant level was set at $\alpha=0.05$.

\section{RESULTS}

\section{Vertical jump height}

There were significant differences in vertical jump height among the groups $(P=0.000)$. In the post boc test, $0 \% \mathrm{BW}$ group was higher than $10 \% \mathrm{BW}(P=0.019), 15 \% \mathrm{BW}(P=0.002)$, and $20 \% \mathrm{BW}$ groups $(P=0.000)$. The $10 \% \mathrm{BW}$ group was greater than $20 \% \mathrm{BW}$ group $(P=0.046)$ (Table 2$)$.

\section{Peak power}

During CMJ, peak power was assessed by GymAware power testing system. Peak powers by increase of additional loads were gradually decreased. However, the differences of peak power were not statistically significant $(P=0.101)$ (Table 2$)$.

\section{Muscle onset time}

Muscle onset times of rectus femoris in knee joint and soleus in ankle joint were evaluated during the CMJ tests. The differences in muscle onset times of rectus femoris $(P=0.918)$ and soleus $(P=$ 0.908 ) by the additional loads were not statistically significant (Table 2).

\section{Rate of force development}

To evaluate RDF by additional loads, RFD to peak EMG amplitude $\left(\mathrm{RFD}_{\text {peak }}\right)$ and Interval RFD ( $\left.\mathrm{RFD}_{\text {interval }}\right)$ were tested. In $\mathrm{RFD}_{\text {peak, }}$, it was shown that $\mathrm{RFD}_{\text {peak }}$ were significantly different in the rectus femoris during the jump $(P=0.032)$. In the post boc test, $\mathrm{RFD}_{\text {peak }}$ of $10 \% \mathrm{BW}$ group was greater than $15 \% \mathrm{BW}(P=0.014)$ and $20 \% \mathrm{BW}$ groups $(P=0.010)$. There were no significant differences in $\mathrm{RFD}_{\text {peak }}$ of the soleus among the groups $(P=0.903)$ (Table 3 , Fig. 1).

In $\mathrm{RFD}_{\text {interval, }}$ the $\mathrm{ANOVA}$ showed that there were significant

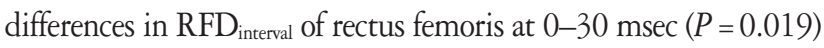
and $0-50 \mathrm{msec}(P=0.037)$. In the post hoc test, the heavier loads groups $(10 \% \mathrm{BW}[P=0.012], 15 \% \mathrm{BW}[P=0.045]$, and $20 \% \mathrm{BW}$ $[P=0.004])$ were higher than $0 \% \mathrm{BW}$ group in $\mathrm{RFD}_{\text {interval }}$ of $0-30$ msec interval. In $0-50$ msec interval, $\mathrm{RFD}_{\text {interval }}$ of $15 \% \mathrm{BW}$ group $(P=0.020)$ and $20 \% \mathrm{BW}$ group $(P=0.008)$ were significantly greater than $0 \% \mathrm{BW}$ group. In $\mathrm{RFD}_{\text {interval }}$ of soleus muscle, those heavier load groups were likely greater than $0 \% \mathrm{BW}$ group at all intervals of 0-30, 0-50, 0-100, and 0-200 msec. However, there was no significant difference among the groups in the intervals (0-30 msec, $P=0.357 ; 0-50 \mathrm{msec}, P=0.478 ; 0-100 \mathrm{msec}, P=$ 0.762; 0-200 msec, $P=0.236$ ) (Table 3, Fig. 2).

\section{Neuromuscular efficiency}

As shown in Table 4, NME of ankle joint was statistically different by additional loads $(P=0.044)$. In the post hoc test, $15 \% \mathrm{BW}$ group $(P=0.024)$ and $20 \% \mathrm{BW}$ group $(P=0.009)$ were greater than $0 \% \mathrm{BW}$ group. NME of knee joint was also increased when 
Table 3. Rate of force development (RFD) of knee and ankle by additional loads

\begin{tabular}{|c|c|c|c|c|c|c|c|}
\hline Variable & & & $0 \%$ & $10 \%$ & $15 \%$ & $20 \%$ & Posthoc \\
\hline \multirow[t]{3}{*}{$\operatorname{RFD}_{\text {peak }}(\mathrm{mV} / \mathrm{msec})$} & \multirow{2}{*}{\multicolumn{2}{|c|}{ Knee }} & $0.007 \pm 0.004$ & $0.010 \pm 0.011^{b, c)}$ & $0.005 \pm 0.005$ & $0.005 \pm 0.002$ & $10 \%>15 \%(P=0.014)$ \\
\hline & & & & & & & $10 \%>20 \%(P=0.010)$ \\
\hline & Ankle & & $0.006 \pm 0.003$ & $0.005 \pm 0.003$ & $0.005 \pm 0.007$ & $0.007 \pm 0.010$ & $\mathrm{NS}(P=0.903)$ \\
\hline \multirow[t]{11}{*}{$\mathrm{RFD}_{\text {interval }}(\mathrm{mV} / \mathrm{msec})$} & \multirow[t]{7}{*}{ Knee } & $30 \mathrm{msec}$ & $0.033 \pm 0.000$ & $0.037 \pm 0.006^{a)}$ & $0.036 \pm 0.004^{b l}$ & $0.004 \pm 0.004^{e l}$ & $10 \%(P=0.012)$ \\
\hline & & & & & & & $0 \%<15 \%(P=0.045)$ \\
\hline & & & & & & & $20 \%(P=0.004)$ \\
\hline & & $50 \mathrm{msec}$ & $0.020 \pm 0.000$ & $0.021 \pm 0.003$ & $0.022 \pm 0.002^{d)}$ & $0.022 \pm 0.002^{e l}$ & $0 \%<10 \%(P=0.020)$ \\
\hline & & & & & & & $0 \%<15 \%(P=0.008)$ \\
\hline & & $100 \mathrm{msec}$ & $0.010 \pm 0.000$ & $0.011 \pm 0.001$ & $0.0011 \pm 0.001$ & $0.011 \pm 0.001$ & $N S(P=0.077)$ \\
\hline & & $200 \mathrm{msec}$ & $0.005 \pm 0.000$ & $0.006 \pm 0.001$ & $0.006 \pm 0.001$ & $0.006 \pm 0.001$ & $N S(P=0.062)$ \\
\hline & \multirow[t]{4}{*}{ Ankle } & $30 \mathrm{msec}$ & $0.033 \pm 0.000$ & $0.037 \pm 0.009$ & $0.038 \pm 0.011$ & $0.004 \pm 0.011$ & $N S(P=0.357)$ \\
\hline & & $50 \mathrm{msec}$ & $0.020 \pm 0.000$ & $0.022 \pm 0.005$ & $0.022 \pm 0.006$ & $0.022 \pm 0.006$ & $N S(P=0.478)$ \\
\hline & & $100 \mathrm{msec}$ & $0.010 \pm 0.000$ & $0.010 \pm 0.002$ & $0.011 \pm 0.003$ & $0.010 \pm 0.002$ & $N S(P=0.762)$ \\
\hline & & $200 \mathrm{msec}$ & $0.005 \pm 0.000$ & $0.005 \pm 0.001$ & $0.005 \pm 0.001$ & $0.006 \pm 0.001$ & $N S(P=0.236)$ \\
\hline
\end{tabular}

Values are presented as mean \pm standard deviation.

$\mathrm{RFD}_{\text {peak, }} \mathrm{RFD}$ to peak EMG amplitude; $\mathrm{RF}$ interval, interval RFDs in time intervals relative to start of jump; NS, not significance.

${ }^{\mathrm{a}} 0 \%$ vs. $10 \%, P<0.05 .{ }^{\mathrm{b}} 0 \%$ vs. $15 \% . P<0.05 .{ }^{\mathrm{c}} 0 \%$ vs. $20 \%, P<0.05 .{ }^{\mathrm{d}} 10 \%$ vs. $15 \% . P<0.05 .{ }^{\mathrm{e}} 0 \%$ vs. $20 \%, P<0.01$.

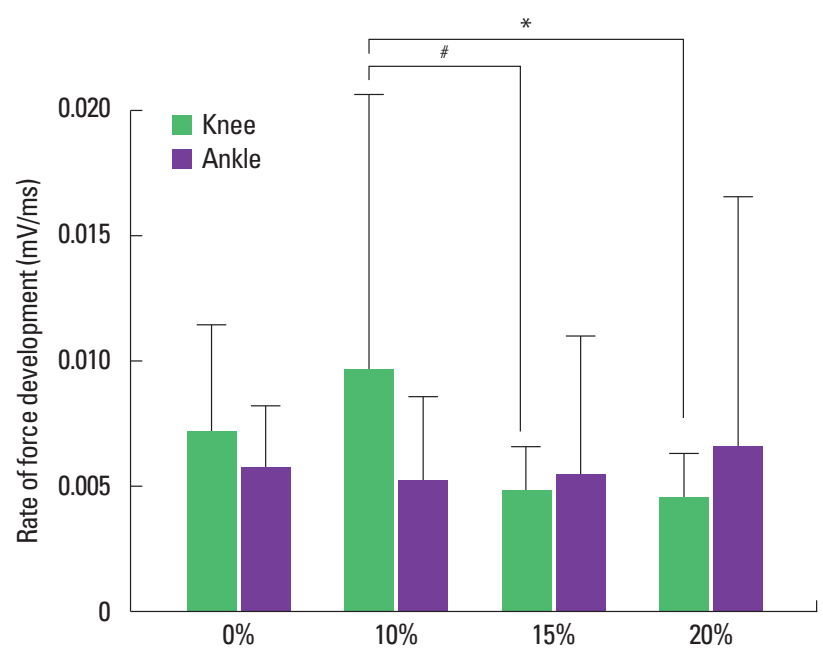

Fig. 1. Rate of force development (mean \pm standard deviation) by additional loads. ${ }^{*} P<0.05,10 \%$ vs. $20 \% .{ }^{\sharp} P<0.05,10 \%$ vs. $15 \%$.

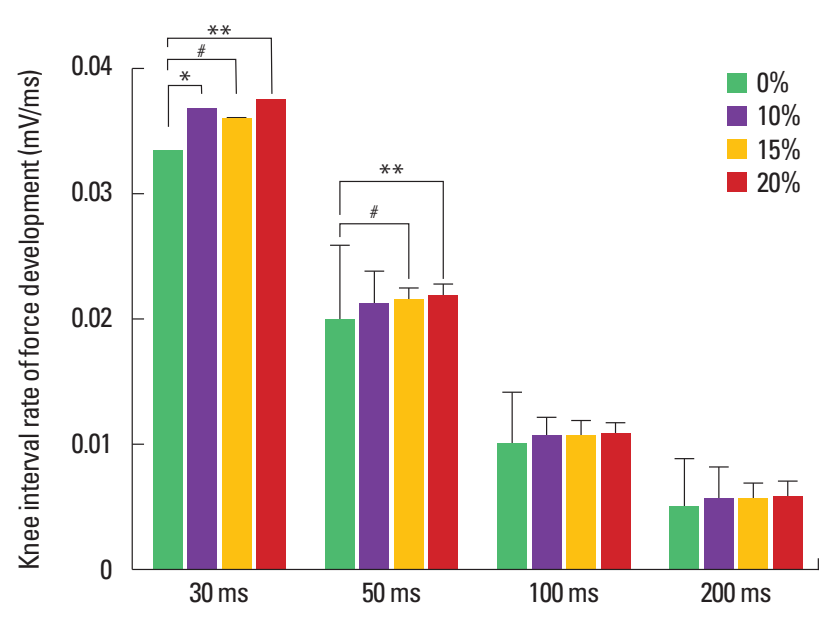

Fig. 2. Interval rate of force development (mean \pm standard deviation) by additional loads. ${ }^{*} P<0.05,0 \%$ vs. $10 \% .{ }^{*} P<0.05,0 \%$ vs. $15 \% .{ }^{*} P<0.01,0 \%$ vs. $20 \%$.

Table 4. Neuromuscular efficiency of knee and ankle by additional loads

\begin{tabular}{lccccc}
\hline Neuromuscular efficiency $(\mathrm{Nm} / \mathrm{mV})$ & $0 \%$ & $10 \%$ & $15 \%$ & $20 \%$ & Post hoc \\
\hline Knee & $1.15 \pm 0.27$ & $1.24 \pm 0.32$ & $1.28 \pm 0.32$ & $1.30 \pm 0.33$ & NS $(P=0.478)$ \\
Ankle & $1.09 \pm 0.16$ & $1.22 \pm 0.27$ & $1.30 \pm 0.30^{\mathrm{a})}$ & $1.33 \pm 0.34^{\mathrm{b})}$ & $0 \%<15 \%(P=0.024)$ \\
& & & & & $0 \%<20 \%(P=0.009)$
\end{tabular}

Values are presented as mean \pm standard deviation.

NS, not significance.

${ }^{a} 0 \%$ vs. $15 \%, P<0.05 .{ }^{b} 0 \%$ vs. $20 \%, P<0.01$ 
additional load was more increased. However, the differences among the groups were not statistically significant $(P=0.478)$.

\section{DISCUSSION}

Plyometric training is popular in sports training to develop motor output, SSC which is related to power and force production (Komi and Bosco, 1978). To increase the neuromuscular output during plyometric training, additional training loads has been incorporated in training programs (Barnes et al., 2015; Kraska et al., 2009).

Additional load during plyometric jump, however, can increase a ground contact time and the increased ground contact time decreases neuromuscular function to produce power (Sáez-Sáez de Villarreal et al., 2010; Santos-Concejero et al., 2013). In plyometric jump training with additional load, setting appropriate additional load is crucial to effectively develop and maximize neuromuscular output.

Thus, this study was performed to identify the effects of additional loads on neuromuscular responses of lower body during plyometric jump and to clarify how much additional load works for enhancing the neuromuscular function.

Vertical jump height is typical variable to assess power ability. In this study, vertical heights of the heavier groups were gradually decreased by increase of additional loads of weight vests. It was shown that $0 \% \mathrm{BW}$ group was higher than the heavier groups (10\%BW, 15\%BW, and 20\% BW).

Heavy additional load seemed to negatively influence on vertical jump. During jump test, the inertia of body increased by added load decreases jumping ability (Cormie et al., 2010). Velocity of movement is a key factor to produce muscle power and RFD (Makaruk et al., 2010; Pereira et al., 2012). The increased inertia caused by the loads of the vests declines a velocity of jump movement and consequently leads to a reduction of power production (Cormie et al., 2008).

Peak power and muscle onset time were not statistically different among the groups. Although there was no significant difference in peak power, it was shown that peak powers in the heavier load groups were reduced. This result also arised from the loads of weight vests. Muscle onset time that is known as effective variable to evaluate how much muscle can quickly activate was assessed during CMJ (Riemann et al., 2002; Vasseljen et al., 2012). The significant differences by additional loads were not appeared. An evaluation of onset time after descending phase of jump in this study had a limitation to identify the muscle activation. In future research, the static starting position would be more effective to assess muscle onset time during jump test (Myers et al., 2003).

RFD means the development of maximal force in minimal time and has been typically defined as an index to assess explosive strength and neuromuscular function (Aagaard et al., 2002; Gruber and Gollhofer, 2004). Also, RFD is known as importance performance variable to evaluate power ability (Van Hooren and Bosch, 2016). In this study, $10 \% \mathrm{BW}$ group was greater than $15 \% \mathrm{BW}$ group and 20\%BW group in RFD to peak EMC amplitude $(P<0.05)$. It means that the increased inertia from the weight vests decreases the jump velocities of the heavier groups $(15 \% \mathrm{BW}, 20 \% \mathrm{BW})$ and consequently, $\mathrm{RFD}_{\text {peak }}$ of the heavier groups were less than 10\%BW group (Pereira et al., 2012; Phillips and Flanagan, 2015). In previous studies, it was reported that added load during jump test reduces jump velocity and peak power and the acceleration of power production was also decreased as additional load was increased (Cormie et al., 2008; Driss et al., 2001). On the other hand, despite of nonsignificant difference between $0 \% \mathrm{BW}$ and $10 \% \mathrm{BW}$ in $\mathrm{RFD}_{\text {peak }}, 10 \% \mathrm{BW}$ group was showed higher than $0 \% \mathrm{BW}$ group. It can be explained that appropriate additional load can work for power production, when fast movement velocity during jump can be maintained. It was reported that a resistance training with high velocity can more effectively develop RFD and muscle power compared with lower velocity training (Balachandran et al., 2014; Schoenfeld et al., 2016).

In interval RFD ( $\left.\mathrm{RFD}_{\text {interval }}\right)$, heavier load groups $(10 \% \mathrm{BW}$, $15 \% \mathrm{BW}$, and $20 \% \mathrm{BW}$ ) were higher than $0 \% \mathrm{BW}$ group at $0-30$ msec and $0-50$ msec time intervals $(P<0.05)$. It means that in the initial phase of jump, greater force is required to start jump quickly in the heavier load groups, because greater development of force and power has to be produced to overcome greater inertia from heavier load (Djuric et al., 2016). Additional load during jump gives rise to increase of eccentric velocity on descending phase and the increased velocity contribute to reflexive mechanism that increases stiffness in muscle and tendon to protect them from injury (Aboodarda et al., 2014; Leukel et al., 2008; McBride et al., 2008) and the increased stiffness intensifies elastic energy generating explosive concentric contraction through stretching-shortening cycle (Argus et al., 2011; Cowan et al., 2001). As a result, by plyometric jump with additional load, the ability to produce power and to increase RFD can be developed.

NME is defined as a ratio of joint moment to muscle activation and is known as an effective variable to evaluate neuromuscular function (Aragão et al., 2015; Bradbury-Squires et al., 2015; Tesch et al., 1990). This variable can be considered as an ability to 
generate a joint moment in relation to muscle activation. Greater joint torque with lower muscle activation can be more efficient (Deschenes et al., 2002).

In this study, it was revealed that $15 \% \mathrm{BW}$ and $20 \% \mathrm{BW}$ groups were greater than $0 \% \mathrm{BW}$ group in NME of ankle joint $(P<0.05)$. Although nonsignificant difference between $10 \% \mathrm{BW}$ and $0 \% \mathrm{BW}$ was found, NME of $10 \% \mathrm{BW}$ group also showed higher than $0 \% \mathrm{BW}$ group. In knee joint, neuromuscular efficiencies of the heavier groups showed higher than $0 \% \mathrm{BW}$ group. It is showed that additional heavy load applied to the body during jumping causes greater inertia in the heavier groups. The increased inertia and fast eccentric contraction result in higher joint moment and then gives rise to enhancement of NME. When load to joint increases, joint stiffness increases in order to reduce negative joint moment and power (Verniba et al., 2017). The stiffness prevents excessive lengthening of structures such as muscle, tendon and ligament, to protect them from the lengthening and simultaneously, enhances SSC effect during eccentric phase of jump (Hughes and Watkins, 2008; Janssen et al., 2012; Makaruk et al., 2010). When heavy load is applied, the protective mechanism that prevents joints flexed or extended excessively, when the body goes down during jump takes place to control center of mass of body and protect structures such as muscle, tendon, or ligament etc. from the load (Leukel et al., 2008).

In force-length principle, the mechanism can place a joint on the appropriate position where muscle can produce greater force (Verniba et al., 2017). The heavier groups generated greater joint moment through the mechanism to control relative greater load compared with $0 \% \mathrm{BW}$ group. The groups take advantage of it the joints place appropriate length position to generate force greatly. Thus, the enhanced joint moment during jump by additional load is advantageous to increase NME.

By the findings of this study, it can be suggested that additional heavy load during plyometric jump training results in enhancement of RFD and $10 \%$ of BW is better as additional load to maximize RFD during CMJ jump compared to the other additional loads. Previous research also reported that plyometric training with using $10 \%-11 \%$ of BW load was effective to enhance a jump ability and power (Luebbers et al., 2003).

This study, however, has some considerations. During the research, jump technique of participants was not controlled. One who has a poor jumping technique might have a problem to control the given loads. Also, percentage of load of weight vest can be changed due to adaptation to training. Thus, additional load has to be monitored and adjusted during plyometric training program.
In conclusion, using additional load during plyometric jump is effective for increase of RFD and NME of lower extremity. Previous studies indicated that weighted-vest jumping is shown to cause development of jump performance in athletic population (Burkett et al., 2005; Thompsen et al., 2007). In this study, it can be indicated that in plyometric jump training with weight vest, additional $10 \%-20 \%$ load of $\mathrm{BW}$ is more effective to develop a neuromuscular response of lower body. $10 \%$ load of BW is especially better to develop RFD compared to other additional loads.

\section{CONFLICT OF INTEREST}

No potential conflict of interest relevant to this article was reported.

\section{ACKNOWLEDGMENTS}

The author appreciates the subjects for participating in this study. The helps of Dr Hong, Dr Hahn, Yongsuk, Dr Hinkel-Lipsker, Dr Li, Dr Nakamura, JD, Coach K, and In-young are much appreciated. This research was supported by the Ministry of Education of the Republic of Korea and the National Research Foundation of Korea (NRF-2015S1A5B5A07044575).

\section{REFERENCES}

Aagaard P, Simonsen EB, Andersen JL, Magnusson P, Dyhre-Poulsen P. Increased rate of force development and neural drive of human skeletal muscle following resistance training. J Appl Physiol (1985) 2002;93: 1318-1326.

Aboodarda SJ, Byrne JM, Samson M, Wilson BD, Mokhtar AH, Behm DG. Does performing drop jumps with additional eccentric loading improve jump performance? J Strength Cond Res 2014;28:2314-2323.

Aragão FA, Schäfer GS, de Albuquerque CE, Vituri RF, de Azevedo FM, Bertolini GR. Neuromuscular efficiency of the vastus lateralis and biceps femoris muscles in individuals with anterior cruciate ligament injuries. Rev Bras Ortop 2015;50:180-185.

Argus CK, Gill ND, Keogh JW, Blazevich AJ, Hopkins WG. Kinetic and training comparisons between assisted, resisted, and free countermovement jumps. J Strength Cond Res 2011;25:2219-2227.

Balachandran A, Krawczyk SN, Potiaumpai M, Signorile JF. High-speed circuit training vs hypertrophy training to improve physical function in sarcopenic obese adults: a randomized controlled trial. Exp Gerontol 2014;60:64-71.

Barnes KR, Hopkins WG, McGuigan MR, Kilding AE. Warm-up with a 
weighted vest improves running performance via leg stiffness and running economy. J Sci Med Sport 2015;18:103-108.

Bosco C, Komi PV. Potentiation of the mechanical behavior of the human skeletal muscle through prestretching. Acta Physiol Scand 1979;106: 467-472.

Bradbury-Squires DJ, Noftall JC, Sullivan KM, Behm DG, Power KE, Button DC. Roller-massager application to the quadriceps and knee-joint range of motion and neuromuscular efficiency during a lunge. J Athl Train 2015;50:133-140.

Burkett LN, Phillips WT, Ziuraitis J. The best warm-up for the vertical jump in college-age athletic men. J Strength Cond Res 2005;19:673-676.

Cormie P, McBride JM, McCaulley GO. Power-time, force-time, and velocity-time curve analysis during the jump squat: impact of load. J Appl Biomech 2008;24:112-120.

Cormie P, McGuigan MR, Newton RU. Adaptations in athletic performance after ballistic power versus strength training. Med Sci Sports Exerc 2010;42:1582-1598.

Cowan SM, Bennell KL, Hodges PW, Crossley KM, McConnell J. Delayed onset of lectromyographic activity of vastus medialis obliquus relative to vastus lateralis in subjects with patellofemoral pain syndrome. Arch Phys Med Rehabil 2001;82:183-189.

Deschenes MR, Giles JA, McCoy RW, Volek JS, Gomez AL, Kraemer WJ. Neural factors account for strength decrements observed after shortterm muscle unloading. Am J Physiol Regul Integr Comp Physiol 2002;282:R578-583.

Djuric S, Cuk I, Sreckovic S, Mirkov D, Nedeljkovic A, Jaric S. Selective effects of training against weight and inertia on muscle mechanical properties. Int J Sports Physiol Perform 2016;11:927-932.

Driss T, Vandewalle H, Quièvre J, Miller C, Monod H. Effects of external loading on power output in a squat jump on a force platform: a comparison between strength and power athletes and sedentary individuals. J Sports Sci 2001;19:99-105.

Faigenbaum AD, McFarland JE, Keiper FB, Tevlin W, Ratamess NA, Kang J, Hoffman JR. Effects of a short-term plyometric and resistance training program on fitness performance in boys age 12 to 15 years. J Sports Sci Med 2007;6:519-525.

Fatouros IG, Jamurtas AZ, Leontsini D, Taxildaris K, Aggelousis N, Kostopoulos N, Buckenmeyer P. Evaluation of plyometric exercise training, weight training, and their combination on vertical jumping performance and leg strength. J Strength Cond Res 2000;14:470-476.

Fouré A, Nordez A, Cornu C. Effects of plyometric training on passive stiffness of gastrocnemii muscles and Achilles tendon. Eur J Appl Physiol 2012;112:2849-2857.

Gruber M, Gollhofer A. Impact of sensorimotor training on the rate of force development and neural activation. Eur J Appl Physiol 2004;92:
98-105.

Guilhem G, Cornu C, Guével A. Neuromuscular and muscle-tendon system adaptations to isotonic and isokinetic eccentric exercise. Ann Phys Rehabil Med 2010;53:319-341.

Häkkinen K. Neuromuscular fatigue in males and females during strenuous heavy resistance loading. Electromyogr Clin Neurophysiol 1994; 34:205-214.

Hoffman JR, Ratamess NA, Cooper JJ, Kang J, Chilakos A, Faigenbaum AD. Comparison of loaded and unloaded jump squat training on strength/power performance in college football players. J Strength Cond Res 2005;19:810-815.

Hughes G, Watkins J. Lower limb coordination and stiffness during landing from volleyball block jumps. Res Sports Med 2008;16:138-154.

Janssen I, Sheppard JM, Dingley AA, Chapman DW, Spratford W. Lower extremity kinematics and kinetics when landing from unloaded and loaded jumps. J Appl Biomech 2012;28:687-693.

Komi PV, Bosco C. Utilization of stored elastic energy in leg extensor muscles by men and women. Med Sci Sports 1978;10:261-265.

Kraska JM, Ramsey MW, Haff GG, Fethke N, Sands WA, Stone ME, Stone $\mathrm{MH}$. Relationship between strength characteristics and unweighted and weighted vertical jump height. Int J Sports Physiol Perform 2009; 4:461-473.

Leontijevic B, Pazin N, Bozic PR, Kukolj M, Ugarkovic D, Jaric S. Effects of loading on maximum vertical jumps: selective effects of weight and inertia. J Electromyogr Kinesiol 2012;22:286-293.

Leukel C, Taube W, Gruber M, Hodapp M, Gollhofer A. Influence of falling height on the excitability of the soleus H-reflex during drop-jumps. Acta Physiol (Oxf) 2008;192:569-576.

Luebbers PE, Potteiger JA, Hulver MW, Thyfault JP, Carper MJ, Lockwood $\mathrm{RH}$. Effects of plyometric training and recovery on vertical jump performance and anaerobic power. J Strength Cond Res 2003;17:704-709.

Makaruk H, Sacewicz T, Czaplick A, Sadowski J. Effect of additional load on power output during jump training. J Hum Kinet 2010;26:31-37.

Markovic G. Does plyometric training improve vertical jump height? A meta-analytical review. Br J Sports Med 2007;41:349-355.

McBride JM, McCaulley GO, Cormie P. Influence of preactivity and eccentric muscle activity on concentric performance during vertical jumping. J Strength Cond Res 2008;22:750-757.

Moore CA, Schilling BK. Theory and application of augmented eccentric loading. Strength Cond J 2005;27:20-27.

Myers JB, Riemann BL, Hwang JH, Fu FH, Lephart SM. Effect of peripheral afferent alteration of the lateral ankle ligaments on dynamic stability. Am J Sports Med 2003;31:498-506.

Nichols TR, Houk JC. Improvement in linearity and regulation of stiffness that results from actions of stretch reflex. J Neurophysiol 1976;39: 
$119-142$.

Pereira A, Izquierdo M, Silva AJ, Costa AM, Bastos E, González-Badillo JJ, Marques MC. Effects of high-speed power training on functional capacity and muscle performance in older women. Exp Gerontol 2012; 47:250-255.

Phillips JH, Flanagan SP. Effect of ankle joint contact angle and ground contact time on depth jump performance. J Strength Cond Res 2015; 29:3143-3148.

Rahman R, Naser B. The effects of plyometric, weight and plyometricweight training on anaerobic power and muscular strength. Phys Edu Sport 2015;3:81-91.

Riemann BL, Myers JB, Lephart SM. Sensorimotor system measurement techniques. J Athl Train 2002;37:85-98.

Sáez-Sáez de Villarreal E, Requena B, Newton RU. Does plyometric training improve strength performance? A meta-analysis. J Sci Med Sport 2010;13:513-522.

Santos-Concejero J, Granados C, Irazusta J, Bidaurrazaga-Letona I, Zabala-Lili J, Tam N, Gil SM. Differences in ground contact time explain the less efficient running economy in north african runners. Biol Sport 2013;30:181-187.

Schoenfeld BJ, Wilson JM, Lowery RP, Krieger JW. Muscular adaptations in low- versus high-load resistance training: a meta-analysis. Eur J Sport Sci 2016;16:1-10.

Tesch PA, Dudley GA, Duvoisin MR, Hather BM, Harris RT. Force and EMG signal patterns during repeated bouts of concentric or eccentric muscle actions. Acta Physiol Scand 1990;138:263-271.

Thompsen AG, Kackley T, Palumbo MA, Faigenbaum AD. Acute effects of different warm-up protocols with and without a weighted vest on jumping performance in athletic women. J Strength Cond Res 2007; 21:52-56.

Van Hooren B, Bosch F. Influence of muscle slack on high-intensity sport performance: a review. Strength Cond J 2016;38:75-87.

Vasseljen O, Unsgaard-Tøndel M, Westad C, Mork PJ. Effect of core stability exercises on feed-forward activation of deep abdominal muscles in chronic low back pain: a randomized controlled trial. Spine (Phila Pa 1976) 2012;37:1101-1108.

Verniba D, Vescovi JD, Hood DA, Gage WH. The analysis of knee joint loading during drop landing from different heights and under different instruction sets in healthy males. Sports Med Open 2017;3:6.

Wilkerson GB, Colston MA, Short NI, Neal KL, Hoewischer PE, Pixley JJ. Neuromuscular changes in female collegiate athletes resulting from a plyometric jump-training program. J Athl Train 2004;39:17-23. 